\title{
Editorial: Manipulation of the cellular microbicidal response and endocytic dynamic by pathogens membrane factors
}

\author{
Benjamin Coiffard ${ }^{1}$, Philippe Soubeyran ${ }^{2}$ and Eric Ghigo ${ }^{3 *}$ \\ ${ }^{1}$ Department of Pulmonology and Lung Transplantation, Hôpital Nord, Marseille, France, ${ }^{2}$ Cellular Stress, Centre de \\ Recherche en Cancérologie de Marseille, Institut National de la Santé et de la Recherche Médicale UMR 1068, Centre \\ National de la Recherche Scientifique UMR 7258, Institut Paoli-Calmettes, Marseille, France, ${ }^{3}$ Faculté de Médecine, \\ URMITE-IRD198, Centre National de la Recherche Scientifique UMR7278, Marseille, France
}

Keywords: planarians, coxiella, body lices, granulomas, ubiquitination, host-pathogens interaction, mycobacteria

\section{OPEN ACCESS}

Edited and reviewed by: Yousef Abu Kwaik, University of Louisville School of Medicine, USA

*Correspondence: Eric Ghigo,

eric.ghigo@univ-amu.fr

Received: 16 April 2015 Accepted: 13 May 2015 Published: 29 May 2015

Citation:

Coiffard B, Soubeyran P and Ghigo E (2015) Editorial: Manipulation of the cellular microbicidal response and endocytic dynamic by pathogens membrane factors.

Front. Cell. Infect. Microbiol. 5:42. doi: 10.3389/fcimb.2015.00042
Microbes such as bacteria, parasites and fungi, have evolved specialized mechanisms to survive and replicate in their host. While high pathogen reproduction is the main purpose to improve next generation growth, adaptation of pathogens to their hosts depends on factors affecting mostly their survival rate. The principle of these mechanisms is to hijack the microbicidal cell function in order to disable and destabilize the host cell defense that. controls and eliminates foreign invaders. Devoid of their defense, cells become permissive to pathogens invasion, a phenomenon that leads to disorders and diseases. To counterstrike the microbicidal functions of the host, microbes use a large arsenal of molecules, known as virulence factors, ranging from proteins and lipids to saccharides. Several evidences highlighted that pathogens use these molecules in order to interfere with the phagolysosome biogenesis, to reprogram signal transduction pathways and, therefore, create a replicative niche.

This special issue covers recent understanding of mechanisms and molecules used by bacterial pathogens such as Coxiella burnetii (LPS), Mycobacterium tuberculosis (LAM) and parasites such as Leishmania (LPG) to interfere with the microbicidal function of cells (e.g., Rab network, ubiquinilation, TLRs signaling). Attention is mainly focused on the reprogramming of the cellular dynamics (granulomas formation), immune response, phagolysosome biogenesis and signal transduction pathways by pathogens. Thus, Vergne and colleagues well summarize the scientific literature on Lipoarabinomannan, a major immunomodulatory lipoglycan found in the cell envelope of Mycobacterium tuberculosis, focusing their attention on its structure and its ability to manipulate the endocytic pathway as well as phagocyte functions (Vergne et al., 2015). In similar manner, the review of Astarie-Dequeker group, address exclusively the role played by phthiocerol dimycocerosates in the modulation of the resident macrophage response (Arbues et al., 2014). Similarly, the composition of the Leishmania lipophosphoglycan, its peculiar chemical structure and what is currently known about its effects favoring parasite virulence in the mammalian host, are the subject of a short perspective written by Forestier et al. (2015). The capacity for bacteria to used LPS to hijack molecular process is highlighted by Conti and colleagues which described how C. burnetii avoids macrophage activation by the disruption of the TLR-2 and TLR-4 association through the reorganization of the macrophage cytoskeleton by C. burnetii LPS (Conti et al., 2015); the same pathogen is the object of the work of Faugaret which have studied the molecular mechanisms of granuloma formation in response to C. burnetii and found that it is that is associated with a core of transcriptional response based on inflammatory genes (Faugaret et al., 2014). Finally, Mottola comments and emphasizes the recent discoveries on bacterial pathogens 
that control the localization or function of the small GTPases Rab5 and Rab7, and therefore modify the maturation from early to late phagosomes (Mottola, 2014). Alomairi and colleagues recapitulate what is currently known about the normal functions of ubiquitination during host cell infection, and they highlight its hijacking to escape clearance and proliferate (Alomairi et al., 2015). It is also important to note that model organisms in the continuous effort to decipher the role of the molecular players involved, contribute strongly to the study of host pathogen interaction and to the discovery of new virulence factors or microbicidal mechanisms: in this special issue, three articles will discuss their invaluable characteristics, with a special attention to the unconventional animal models called also exotic models or ExoMod (Conti et al., 2014; Abnave et al., 2015; Coulaud et al., 2015).

\section{References}

Abnave, P., Conti, F., Torre, C., and Ghigo, E. (2015). What RNAi screens in model organisms revealed about microbicidal response in mammals? Front. Cell. Infect. Microbiol. 4:184. doi: 10.3389/fcimb.2014.00184

Alomairi, J., Bonacci, T., Ghigo, E., and Soubeyran, P. (2015). Alterations of host cell ubiquitination machinery by pathogenic bacteria. Front. Cell. Infect. Microbiol. 5:17. doi: 10.3389/fcimb.2015.00017

Arbues, A., Lugo-Villarino, G., Neyrolles, O., Guilhot, C., and Astarie-Dequeker, C. (2014). Playing hide-and-seek with host macrophages through the use of mycobacterial cell envelope phthiocerol dimycocerosates and phenolic glycolipids. Front. Cell. Infection Microbiol. 4:173. doi: 10.3389/fcimb. 2014.00173

Conti, F., Abnave, P., and Ghigo, E. (2014). Unconventional animal models: a booster for new advances in host-pathogen interactions. Front. Cell. Infection Microbiol. 4:142. doi: 10.3389/fcimb.2014.00142

Conti, F., Boucherit, N., Baldassarre, V., Trouplin, V., Toman, R., Mottola, G., et al. (2015). Coxiella burnetii lipopolysaccharide blocks p38alpha-MAPK activation through the disruption of TLR-2 and TLR-4 association. Front. Cell. Infection Microbiol. 4:182. doi: 10.3389/fcimb.2014.00182

Coulaud, P. J., Lepolard, C., Bechah, Y., Berenger, J. M., Raoult, D., and Ghigo, E. (2015). Hemocytes from Pediculus humanus humanus are hosts for human bacterial pathogens. Front. Cell. Infection Microbiol. 4:183. doi: 10.3389/fcimb.2014.00183

Faugaret, D., Ben Amara, A., Alingrin, J., Daumas, A., Delaby, A., Lepolard, C., et al. (2014). Granulomatous response to Coxiella burnetii, the agent of Q fever: the lessons from gene expression analysis. Front. Cell. Infection Microbiol. 4:172. doi: $10.3389 /$ fcimb. 2014.00172
The issue of drug resistance is as old as antibiotics themselves, but so far very few steps have been undertaken to reduce the impact of this threatening public health menace. Beyond the variety of novel approaches being utilized by biotech companies, fundamental research is essential to elucidate how microbes replicate in the host, how molecular players are involved in the host-parasite interactions and how intracellular pathogens finally could become resistant to drugs. Conversely, the capacity of pathogens to perturb the microbicial response can be used to define new therapeutic strategies, and as tools to investigate cells properties: Gorvel and colleagues exploited C. burnetii and Brucella abortus as tools to elucidate the role of a specific subpopulations of Dendritic cells, the decidual Dendritic cells (dDCs), in placental immune system (Gorvel et al., 2015).

Forestier, C. L., Gao, Q., and Boons, G. J. (2015). Leishmania lipophosphoglycan: how to establish structure-activity relationships for this highly complex and multifunctional glycoconjugate? Front. Cell. Infection Microbiol. 4:193. doi: $10.3389 /$ fcimb. 2014.00193

Gorvel, L., Ben Amara, A., Ka, M. B., Textoris, J., Gorvel, J. P., and Mege, J. L. (2015). Myeloid decidual dendritic cells and immunoregulation of pregnancy: defective responsiveness to Coxiella burnetii and Brucella abortus. Front. Cell. Infection Microbiol. 4:179. doi: 10.3389/fcimb.2014. 00179

Mottola, G. (2014). The complexity of Rab5 to Rab7 transition guarantees specificity of pathogen subversion mechanisms. Front. Cell. Infection Microbiol. 4:180. doi: 10.3389/fcimb.2014. 00180

Vergne, I., Gilleron, M., and Nigou, J. (2015). Manipulation of the endocytic pathway and phagocyte functions by Mycobacterium tuberculosis lipoarabinomannan. Front. Cell. Infection Microbiol. 4:187. doi: $10.3389 /$ fcimb. 2014.00187

Conflict of Interest Statement: The authors declare that the research was conducted in the absence of any commercial or financial relationships that could be construed as a potential conflict of interest.

Copyright (C) 2015 Coiffard, Soubeyran and Ghigo. This is an open-access article distributed under the terms of the Creative Commons Attribution License (CC BY). The use, distribution or reproduction in other forums is permitted, provided the original author(s) or licensor are credited and that the original publication in this journal is cited, in accordance with accepted academic practice. No use, distribution or reproduction is permitted which does not comply with these terms. 